\title{
Quitting smoking: experiences from the Southwestern region, Saudi Arabia.
}

\author{
Awad S. Alsamghan* \\ Family and Community Medicine Department, College of Medicine, King Khalid University, Abha, Kingdom of Saudi \\ Arabia
}

\begin{abstract}
Background: Tobacco a huge global public health problem with 1.3 billion smokers worldwide contributed to $8.8 \%$ of all deaths and $4.1 \%$ of DALYs. Current prevalence of tobacco in Saudi is $12.1 \%$ considering the extent of tobacco smoking as a health issue.

Objective: This study aims to find out the smoking patterns, quitting trials and determinants of smoking cessation among smokers in Aseer region.

Methods: This study was conducted in six main antismoking clinics located in Abha city, Aseer region using a purposive sampling technique, this medical-record based, retrospective cohort study included data of all smokers (695) who attended the centers for the sake of quitting smoking.

Results: A small percentage (12.8\%) had successfully quit smoking i.e. they were smoking free for more than one year. A large proportion $\mathbf{( 7 8 . 3 \%}$ ) reported a previous attempt to quit smoking. Among those who tried to quit smoking, the number of trials ranged from to 1 to 6 times with an average of $2.34 \pm$ 1.46 times and a median of 2 times. The average age of those trying to quit smoking $(30.69+10.18$ years) was significantly $(t=2.127, P=0.034)$ lower than the corresponding figures of those who did not $(32.69 \pm$ 10.31 y).

Conclusion: A good proportion of the respondents have a desire to quit and attempts quitting. The tobacco control program in Saudi Arabia has made great efforts with setting up of smoking cessation clinics that are manned with family physicians.
\end{abstract}

Keywords: Smoking, Tobacco, Quitting, Saudi Arabia, Ministry of Health.

Accepted on May 4, 2018

\section{Introduction}

Tobacco in its various forms of use is a huge global public health problem with 1.3 billion smokers worldwide. In an initial estimate of factors responsible for the global burden of disease, tobacco contributed to $8.8 \%$ of all deaths and $4.1 \%$ of DALYs [1]. In Saudi Arabia, tobacco smoking is emerging as a gross public health problem among young and older adults. This has been confirmed through the recent report of the Saudi Health Interview Survey [2], a large national survey developed in partnership between the Ministry of Health in Saudi Arabia and the Institute for Health Metrics and Evaluation of the University of Washington, which was conducted in 2013 in all Saudi regions and included 10,827 participants. Overall, 12.1\% of Saudis reported that they currently smoke tobacco. Males accounted for majority of the current as well as daily smokers, however a small percentage of female smokers was also revealed [2].

Considering the extent of tobacco smoking as a health issue, it is essential that public health experts should concentrate on smoking cessation activities and programs. Irrespective of age, quitting smoking is beneficial to health, so much so, that if a smoker quits before the age of 35 years have his premature mortality rates are similar to those of persons who never smoked $[3,4]$. The prevalence of cigarette smoking among adults (aged $\geq 18 \mathrm{y}$ ) in the United States decreased from $42.4 \%$ to $18.1 \%$, over the past four decades. This decline is explained partly due to increase in smoking cessation $[3,4]$. In the Saudi study, almost half of the smokers; i.e. $49.1 \%$ reported having attempted to quit smoking within the last 12 months [2].

In Saudi Arabia, the Tobacco Control Program is affiliated to the Ministry of Health (MOH). It was established in 2002. The program provides scientific and advisory services on all aspects of smoking awareness and its harms as well as methods to combat it. It also oversees a series of tobacco control clinics set up in a number of cities in the Kingdom. The policy of this programme includes a number of factors including offering help to quit and warning of the dangers of tobacco [5].

The use of counselling, along with smoking cessation aids like nicotine replacement therapy, can improve the chances of successful smoking cessation [6]. Clinical trials provide strong evidence that pharmacotherapy for smoking cessation, including various forms of Nicotine Replacement Therapies (NRT), bupropion or varenicline, greatly increases the chances of a successful smoking cessation attempt $[7,8]$. 
Saudi Ministry of health has established smoking cessation clinics, equipped with trained personnel, to offer free consultation as well as provision of free NRT for the full course of treatment [5]. Notwithstanding, a notable finding in the Saudi study pointed that just a little more than half of the smokers reported having been advised by their physician or a health care professional to quit smoking during any visit within the last year.

Quitting has been described as an elaborate process that needs to be understood for optimizing interventions. Moreover, there is a need to explore the reasons for quitting and the choice of methods to assist quitting. The information, about previous quitting attempts, experiences and preferences could help in guiding the future attempts at quitting and improve chances of successful quitting. This would in turn, ensure efficient use of clinicians' time and limited healthcare resources [9].

A number of studies in Saudi Arabia have focused on the epidemiology of smoking [10,11]. However, there is lack of information on the other important aspect, i.e. smoking cessation. This study aims to find out the smoking patterns, quitting trials and determinants of smoking cessation among smokers in Aseer region. It hopes to provide seminal information on these aspects, which would provide a better understanding of the smoking control programme in Saudi Arabia, particularly in Aseer region.

\section{Method}

Study setting: This study was conducted in the main antismoking clinics located in Abha city, the capital of Aseer region, Southwestern Saudi Arabia. The smoking-cessation clinics are six specialized clinics covered mainly by family doctors, having special training in smoking cessation. The centers are also equipped with pharmacy containing most commonly used medications in smoking cessation and are dispensed free of cost for the entire treatment period for the patients. Study period: The study extended for a period of eleven months, from January to November 2016. Study procedure: Using a purposive sampling technique, this medical-record based, retrospective cohort study included data of all smokers (695) who attended the centers for the sake of quitting smoking during the study period. Information was collected on a data driven form, based on the patient record maintained in the smoking-cessation clinic. A group of five intern doctors helped to collect the data. Any incomplete records were excluded. Study tool: The data collected include patient characteristics including: Age, gender, marital status, educational and occupational status, residence ownership, residential area, monthly family income and any smoker family member. Smoking characteristics included age at starting smoking, reason for starting smoking, number of cigarettes smoked per day, morning smoking, desire to quit, previous quitting trials, longest period of abstinence, reasons for wanting to quit, knowledge of side effects, use of medication for quitting and type of quitting aid (medication used).

\section{Data analysis}

Data was coded and entered into SPSS 20. Descriptive statistics (frequency, percentage, mean and standard deviation) was used to present the basic data about patient sociodemographic and smoking characteristics, quitting characteristics and reasons for quitting attempt. Chi square and t-test was used to find association between the various sociodemographic and smoking characteristics and quitting attempt.

\section{Results}

The present study included 695 smokers who attended antismoking clinics during the study period. The age of the study group ranged between 14-80 y, with a mean age of $31.13 \mathrm{y}$, and a standard deviation of $10.23 \mathrm{y}$. The basic characteristics are described in Table 1.

Almost all $(99.3 \%)$ of the smokers were males. About $41 \%$ were educated to secondary school level and $(46.8 \%)$ university level. While $22.6 \%$ of our respondents were still students, more than half $(51.1 \%)$ were government employees. Unemployment was not commonly found in the study group. The income level of respondents varied widely and was equally distributed between most groups as depicted in the table. More than one-fifth of our study population $(23.8 \%)$ reported not having a fixed income. Fifty eight percent of the respondents were married and house ownership was reported by about half of them. More than half of the respondents $(54.4 \%)$ reported having a smoker within their family.

\section{Smoking practices of the study group}

Table 2 describes the smoking practices of the study group. The age at initiation shows that most of the respondents started smoking in their adolescence $(67.8 \%)$, with cigarette being the most common type of agent used (61.6\%).In more than $47 \%$ smokers, the influence to smoke was from their friends. About $40 \%$ smokers reported using 11-20 cigarettes per day, and $46.2 \%$ reported having the first cigarette in the morning within 5 min of waking.

\section{Quitting characteristics}

Out of a total of 695 smokers, small percentage (12.8\%) had successfully quit smoking i.e. they were smoking free for more than one year. Fifty four percent reflected a desire to quit, while about one third were still undecided about quitting (Figure 1). A large proportion i.e. 544 (78.3\%) reported a previous attempt to quit smoking. Among those who tried to quit smoking, the number of trials ranged from to 1 to 6 times with an average of $2.34 \pm 1.46$ times and a median of 2 times. The longest period of quitting smoking ranged from 1 day to 360 days with an average of $31.1 \pm 52.9 \mathrm{~d}$ and a median of $7 \mathrm{~d}$. Table 3 describes reasons mentioned among those who tried to quit smoking. The mostly frequent mentioned reasons were health and religious. The majority of those who tried to quit smoking (407, 74.8\%) were not using any medication to stop smoking. Among those who used medication $(n=137)$, 
champix (vareniclline) was the most frequently used drug $(52.6 \%)$ (Table 4).

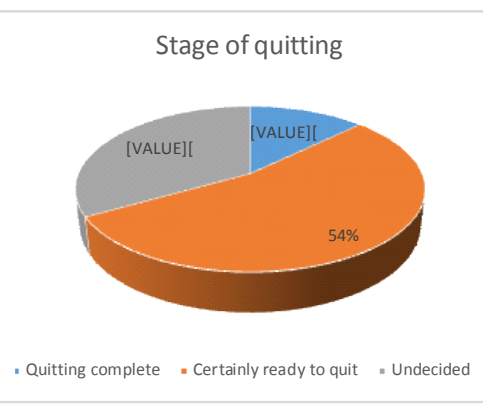

Figure 1. Stage of quitting by the study group at enrolment in the program.

The average age of those trying to quit smoking $(30.69 \pm 10.18$ y) was significantly lower $(\mathrm{t}=2.127, \mathrm{P}=0.034)$, than the corresponding figures of those who did not (32.69 $\pm 10.31 \mathrm{y})$.

Table 5 shows the univariate analysis of factors that affected attempts to quit smoking. The table shows that significantly more smokers of younger age attempted quitting smoking as compared to older $(\mathrm{COR}=1.497,95 \% \mathrm{CI}=1.038-2.159)$. Also, married subjects attempted quitting smoking significantly more than the singles $(\mathrm{COR}=1.631,95 \% \mathrm{CI}=1.115-2.386)$. Those who experienced smoking related disease attempted quitting significantly more than those who did not $(\mathrm{COR}=1.69,95 \%$ $\mathrm{CI}=1.09-2.59$ ). People in private jobs were more likely to attempt quitting smoking, though it was not significant. On the other hand, education, income, home ownership, number of daily cigarette smoking, having any chronic disease having any smoker in the family were of no significant association with smoking quitting trial.

Table 1. Basic socio-demographic characteristics of smokers attending the anti-smoking clinics.

\begin{tabular}{lll}
\hline Patient characteristic & Number & $\%$ \\
\hline Age & & \\
\hline$<20$ & 70 & 10.1 \\
\hline $20-29$ & 265 & 38.1 \\
\hline $30-39$ & 242 & 34.8 \\
\hline $40-49$ & 74 & 10.7 \\
\hline$>50$ & 44 & 6.3 \\
\hline Gender & & 99.3 \\
\hline Male & 690 & 0.7 \\
\hline Female & 5 & 1 \\
\hline Education Level & & 2.6 \\
\hline Illiterates & 70 & \\
\hline Primary & 40 & \\
\hline Intermediate & & \\
\hline
\end{tabular}

\begin{tabular}{|c|c|c|}
\hline Secondary & 288 & 41.4 \\
\hline University & 325 & 46.8 \\
\hline Postgraduate & 17 & 2.4 \\
\hline \multicolumn{3}{|l|}{ Work } \\
\hline Unemployed & 11 & 1.6 \\
\hline Student & 157 & 22.6 \\
\hline Govt. Job & 355 & 51.1 \\
\hline Private & 104 & 15 \\
\hline Others & 68 & 9.7 \\
\hline \multicolumn{3}{|l|}{ Income } \\
\hline No fix income & 165 & 23.8 \\
\hline$<3000 \mathrm{SR}$ & 101 & 14.5 \\
\hline $3000-6000$ SR & 118 & 17 \\
\hline $6001-10000 \mathrm{SR}$ & 167 & 24 \\
\hline >10000 SR & 144 & 20.7 \\
\hline \multicolumn{3}{|l|}{ Marital Status } \\
\hline Married & 407 & 58.6 \\
\hline Single & 288 & 41.4 \\
\hline \multicolumn{3}{|l|}{ Home } \\
\hline Own & 342 & 49.2 \\
\hline Rented & 353 & 50.8 \\
\hline \multicolumn{3}{|c|}{ Smoker in family member } \\
\hline Yes & 378 & 54.4 \\
\hline No & 317 & 45.6 \\
\hline
\end{tabular}

Table 2. Smoking characteristics of the study population.

\begin{tabular}{lll}
\hline Types of smoking & Number & $\%$ \\
\hline Cigarette & 428 & 61.6 \\
\hline Shishah & 21 & 3 \\
\hline Cigar & 3 & 0.4 \\
\hline Cigarette and Shishah & 34 & 4.9 \\
\hline Cigarette and Tinbak & 182 & 26.2 \\
\hline More than two types of tobacco use & 27 & 3.9 \\
\hline Age at starting smoking & & \\
\hline$\leq 10$ & 14 & 2 \\
\hline $11 / 19$ & 471 & 67.8 \\
\hline $20-29$ & 200 & 28.8 \\
\hline 30 and above & 10 & 1.4 \\
\hline Influence for starting of smoking & & \\
\hline Friends & 330 & 47.5 \\
\hline
\end{tabular}




\begin{tabular}{lcc}
\hline Co-workers & 65 & 9.3 \\
\hline Family & 20 & 2.9 \\
\hline Stress & 118 & 17 \\
\hline Advertisement & 28 & 4 \\
\hline Combination of the above & 41 & 5.9 \\
\hline Friends and co-workers & 31 & 4.5 \\
\hline Friends and Stress & 62 & 8.9 \\
\hline Cigarette consumption per day & & \\
\hline $1 / 10$ & 190 & 27.3 \\
\hline $11 / 20$ & 283 & 40.7 \\
\hline $21-30$ & 134 & 19.3 \\
\hline$>31$ & 88 & 12.7 \\
\hline
\end{tabular}

\begin{tabular}{lcc}
\hline Varenicline (Champix) & 72 & 52.6 \\
\hline Nicotine patch & 40 & 29.2 \\
\hline Nicotine lozenge & 13 & 9.5 \\
\hline Nicotinell & 4 & 2.9 \\
\hline Champix+nicotine patch & 4 & 2.9 \\
\hline Champix+nicotinell & 1 & 0.7 \\
\hline Others & 3 & 2.2
\end{tabular}

Table 5. Relationship of quitting attempt with socio-demographic factors.

\begin{tabular}{|c|c|c|c|c|c|}
\hline \multirow[t]{2}{*}{ Variables } & \multicolumn{4}{|c|}{ Previous quitting attempt } & \multirow[t]{2}{*}{ p-value ${ }^{*}$} \\
\hline & \multicolumn{2}{|c|}{ Yes $(N=544)$} & \multicolumn{2}{|c|}{ No $(\mathrm{N}=151)$} & \\
\hline \multicolumn{6}{|l|}{ Age } \\
\hline$>20$ & 58 & 82.9 & 12 & 17.1 & 0.174 \\
\hline $20-29$ & 216 & 81.5 & 49 & 18.5 & \\
\hline $30-39$ & 186 & 76.9 & 56 & 23.1 & \\
\hline $40-49$ & 52 & 70.3 & 22 & 29.7 & \\
\hline 50 up & 32 & 72.7 & 12 & 27.3 & \\
\hline \multicolumn{6}{|l|}{ Education level } \\
\hline Illiterate & 6 & 85.7 & 1 & 14.3 & 0.77 \\
\hline Primary & 13 & 72.2 & 5 & 27.8 & \\
\hline Intermediate & 28 & 70 & 12 & 30 & \\
\hline Secondary & 227 & 78.8 & 61 & 21.2 & \\
\hline University & 256 & 78.8 & 69 & 21.2 & \\
\hline Postgraduate & 14 & 82.4 & 3 & 17.6 & \\
\hline \multicolumn{6}{|l|}{ Income } \\
\hline No fix income & 129 & 78.2 & 36 & 21.8 & 0.47 \\
\hline Less than 3000 & 82 & 81.2 & 19 & 18.8 & \\
\hline $3000-6000$ & 98 & 83.1 & 20 & 16.9 & \\
\hline $6001-10000$ & 127 & 76 & 40 & 24 & \\
\hline More than 10000 & 108 & 75 & 36 & 25 & \\
\hline \multicolumn{6}{|l|}{ Job } \\
\hline Jobless & 10 & 90.9 & 1 & 9.1 & 0.06 \\
\hline Student & 126 & 80.3 & 31 & 19.7 & \\
\hline Government & 264 & 74.4 & 91 & 25.6 & \\
\hline Private & 90 & 86.5 & 14 & 13.5 & \\
\hline Others (e.g. Retired) & 54 & 79.4 & 14 & 20.6 & \\
\hline \multicolumn{6}{|l|}{ Marital status } \\
\hline Married & 305 & 74.9 & 102 & 25.1 & 0.01 \\
\hline Single & 239 & 83 & 49 & 17 & \\
\hline
\end{tabular}

\begin{tabular}{llc}
\hline Reasons for attempting a quitting trial & Number & $\%$ \\
\hline Religious & 82 & 11.8 \\
\hline Health & 107 & 15.4 \\
\hline Economic & 20 & 2.9 \\
\hline Social & 26 & 3.7 \\
\hline Religious and health & 152 & 21.9 \\
\hline Religious and economic & 11 & 1.6 \\
\hline Religious and Social & 38 & 5.5 \\
\hline Religious, health and social & 127 & 18.3 \\
\hline Religious, health, social and economic & 117 & 16.7 \\
\hline No particular reason & 15 & 2.2
\end{tabular}

Table 4. Use and type of nicotine replacement therapy in quitting.

\begin{tabular}{lccc}
\hline Use of medication in previous quitting trial & Number & $\%$ \\
\hline No & 407 & 74.8 \\
\hline Yes & 137 & 25.2 \\
\hline Medication used $^{*}$ & &
\end{tabular}

Morning smoking

\begin{tabular}{lcc}
\hline Within first five minutes & 321 & 46.2 \\
\hline After 31-60 min from waking & 203 & 29.2 \\
\hline After one hour & 171 & 24.6 \\
\hline
\end{tabular}

Smoking side effects ( ${ }^{*} \mathrm{HTN}, \mathrm{IHD}, \mathrm{COPD}$, teeth staining, cough, bad smell).

\begin{tabular}{lcc}
\hline Yes & 202 & 29.1 \\
\hline No & 493 & 70.9 \\
\hline
\end{tabular}

*HTN: Hypertension; IHD: Ischemic Heart Disease; COPD: Chronic Obstructive Pulmonary Disease.

Table 3. Reasons for attempted quitting among the smokers. 


\begin{tabular}{lccccc}
\hline $\begin{array}{l}\text { Smoke } \\
\text { (HTN ,IHD, COPD) }\end{array}$ & disease & & & & \\
\cline { 1 - 5 } No & 374 & 75.8 & 119 & 24.2 & $<0.01$ \\
\cline { 1 - 5 } Yes & 170 & 84.1 & 32 & 15.9 & \\
\hline
\end{tabular}

Significance $(p<0.05)$; HTN: Hypertension; IHD: Ischemic Heart Disease; COPD: Chronic Obstructive Pulmonary Disease.

\section{Discussion}

The present study included 695 smokers who attended antismoking clinics in Aseer region. Most of the smokers were young males about one fourth being students. Most of the respondents started smoking in their adolescence and friends were the most common influence to start smoking. All these findings are supported by existing smoking literature. Smoking in the United States has displayed prevalence among those aged 18-30 $\mathrm{y}$ is the highest of all adult age groups [12].

In the current study, $78.3 \%$ smokers reported a previous attempt to quit smoking, and most of them expressed a desire to quit. These are positive findings as attempted quitting indicates seriousness in the smoker's attitude to cease smoking and is considered as the final stage in the process of contemplation and preparation for quitting [13]. In studies on some Western populations, $10-20 \%$ of smokers report planning to quit or seriously thinking about making an attempt in the next month [14]. Other studies have found higher proportions (46\%) of smokers saying that they intend to quit within the next year [15]. A prospective cohort study across four western countries reported $82.0 \%$ of smokers having made any quit attempts at recruitment. In a US study, $65.9 \%$ smokers reported attempts at quitting [16].

Among those who tried to quit smoking, the number of trials ranged from to 1 to 6 times and the longest period of quitting smoking ranged from 1 day to $360 \mathrm{~d}$.

The four country study revealed that though most quit attempts end rapidly, the majority of smokers succeeded in staying quit for more than 1 month and around one third could stop for more than 6 months [16]. In this study, 12.8\% smokers had successfully quit smoking i.e. they were smoking free for more than one year.

A similar finding has been observed in the four country study that reported $15.5 \%$ successful quitters.

The findings in the present study point that younger smokers reported more quitting desire than the older smokers. The average age of those trying to quit smoking at $30.69 \pm 10.18 \mathrm{y}$ was significantly lower than the corresponding figures of those who did not. This finding finds support in a US study that reported lower quit attempts in older age groups [16]. In the four country study, findings revealed that those with prior attempts were more likely to be older and female. Quitting smoking is beneficial to health at any age, and cigarette smokers who quit before age 35 years have mortality rates similar to those of persons who never smoked [16]. Another socio-demographic factor that significantly affected quitting behavior was marital status; with married subjects significantly more likely to attempt quitting smoking as compared to singles.

The mostly frequent mentioned motivations for quitting attempts were health and religious reasons. Although the Saudi government has raised taxes over imported cigarettes to $100 \%$ [5] this does not seem to affect the smokers enough to act as a motivator for quitting, probably due to a high per capita GDP in the kingdom. Studies have revealed many motivators for quitting. Among Japanese smokers, the rise in cigarette prices was reported as a main motivator especially among the nicotine dependent [17]. Other studies reported that smokers acknowledged that concerns or problems related to personal health as motivating factors for stopping smoking [18].

Researchers, advocates and healthcare practitioners have emphasized that the chances of quitting successfully can be increased by using Nicotine-Replacement Therapy (NRT), or other pharmacotherapies like bupropion and varenicline. This could be complemented with behavioral support in the form of counseling from a healthcare professional $[5,19]$. However, it is revealed from studies that most quit attempts are unassisted [20] and most smokers quit without pharmacological or professional assistance [21]. Qualitative studies on smoking and quitting behaviors have reported a number of interesting factors that inhibit the smokers from effective seeking and utilization of healthcare. Not seeking help for quitting seems not to result from a lack of knowledge about the assistance available, but due to complex factors like evaluation of the perceived costs and benefits of using assistance compared with the costs and benefits of quitting unassisted. Many participants assumed that quitting is their individual responsibility or identified quitting without any assistance to be the 'right' or 'better' option [21]. In these studies, the subjects who quit on their own were reluctant to consult their physician, basically as they did not view smoking or quitting as an illness [22,23].

The present study also focused on the use and type of pharmacotherapy used in quitting trials. There are many studies that have reported increased cessation rates with the use of pharmacotherapy [24,25], but in the current study, more than three quarters of those who tried to quit smoking were not using any medication to stop smoking. Among those who used medication $(\mathrm{n}=125)$, verincline was the most frequently used drug (54.4\%). In this study, the use of NRT did not show any association with successful quitting. Though this finding is similar to population-based studies that have shown no difference in cessation rates between those who use and those who do not use pharmacotherapy [12,26,27], it points to inadequate counseling process and suggests a lack of knowledge regarding use and benefits of using pharmacotherapy for quitting smoking.

Helping tobacco users to quit can reduce tobacco-related disease, death, and health care costs $[3,28]$. Increasing taxes on tobacco products, passing and implementing indoor smoke free laws, improving health insurance coverage of cessation services, and integrating tobacco dependence treatment into 
routine clinical care have all helped increase cessation rates $[3,28]$.

\section{Conclusion}

The study findings conclude that a good proportion of the respondents have a desire to quit and attempts quitting. The findings of this study point to an association between quitting attempts and patient characteristics (younger smokers, married smokers, and smokers suffering from side effects). These findings suggest that smoking cessation services can be targeted to these groups in order to improve the utilization of services. The tobacco control program in Saudi Arabia has made great efforts with setting up of smoking cessation clinics that are manned with family physicians, which is an advantage as they have the ability to manage comorbidities like DM,HTN, asthma or psychiatric problems like depression and anxiety, besides offering full course of free NRT for attempters. It is expected that the study findings will help in better directing of the smoking cessation services and consequently improve the utilization of existing services in the tobacco control program in this region.

\section{Acknowledgement}

The author wishes to acknowledge Dr. Aesha Siddiqui, Assistant professor, Department of Family and Community Medicine King Khalid University for her expert guidance in bringing this work into its present form. Appreciation is also extended to the interns and clinical staff at the PHCCs, without whose help this work would not have been possible.

\section{References}

1. WHO report on the global tobacco epidemic 2015.

2. Saudi Health Interview Survey. http: // www.healthdata.org/sites/default/ files/files/Projects/KSA/ Smoking-KSA-Findings-from-the-Saudi-HealthInterview-Survey.pdf. Retrieved on March 8, 2017.

3. U.S. Department of Health and Human Services. The health consequences of smoking-50 years of progress: a report of the surgeon general. Atlanta, GA: U.S. Department of Health and Human Services, Centers for Disease Control and Prevention, National Center for Chronic Disease Prevention and Health Promotion, Office on Smoking and Health, 2014.

4. Xu F, Town M, Balluz LS, Bartoli WP, Murphy W, Chowdhury PP. Surveillance for certain health behaviors among states and selected local areas-United States, 2010. MMWR Surveill Sum 2013; 63: 1.

5. Al-Munif. Report on tobacco control program of Ministry of Health in Saudi Arabia Ministry of Health, Riyadh, 2009.

6. Stead LF, Buitrago D, Preciado N. Physician advice for smoking cessation. Cochrane Database Syst Rev 2013; 5: 000165 .

7. Cahill K, Stevens S, Perera R. Pharmacological interventions for smoking cessation: an overview and network meta-analysis. Cochrane Database Syst Rev 2013; 5: 009329

8. Raupach T, van Schayck CP. Pharmacotherapy for smoking cessation: current advances and research topics. CNS Drugs 2011; 25: 371-382.

9. Thomas D, Abramson MJ, Bonevski B. Quitting experiences and preferences for a future quit attempt: a study among inpatient smokers. BMJ Open 2015; 5: 006959 .

10. Bassiony MM. Smoking in Saudi Arabia. Saudi Med J 2009; 30: 876-881.

11. Siddiqui S, Ogbeide DO, Al Khalifa I. Smoking in a Saudi community: prevalance, influencing factors, and risk perception. Fam Med 2001; 33: 367-370.

12. Buller DB, Halperin A, Severson HH, Borland R, Slater $\mathrm{MD}$, Erwin P. Effect of nicotine replacement therapy on quitting by young adults in a trial comparing cessation services. J Public Health Manag Pract 2014; 20: 7-15.

13. Borland R, Partos TR, Yong HH, Cummings KM, Hyland A. How much unsuccessful quitting activity is going on among adult smokers? Data from the International Tobacco Control Country Cohort Survey Addiction 2012; 107: 673-682.

14. Kaida A, Edwards J, Fraser-Lee N, Kunyk D, Lightfoot P, Marko J, Spence JC, Spinola C. Smoking in the Capital Health Region-Report, Population Health Survey 2002. Edmonton, Alberta Capital Health 2004.

15. West R, McEwen A, Bolling K, Owen L. Smoking cessation and smoking patterns in the general population: a 1-year follow-up. Addiction 2001; 96: 891-902.

16. René Lavinghouze S, Ann M, Amal J, Linda N, Karen D, Laura W. Trends in quit attempts among adult cigarette smokers-United States, 2001-2013. MMWR Morb Mortal Wkly Rep 2015; 64: 1129-1135.

17. Tanihara S, Momose Y. Reasons for smoking cessation attempts among Japanese male smokers vary by nicotine dependence level: a cross-sectional study after the 2010 tobacco tax increase. BMJ Open 2015; 5: 006658.

18. Ministry of Health, Labour and Welfare. The survey for smoking and health problems in Japan 2017.

19. Stead LF, Lancaster T. Group behaviour therapy programmes for smoking cessation. Cochrane Database Syst Rev 2009; 2: 001007.

20. Edwards SA, Bondy SJ, Callaghan RC. Prevalence of unassisted quit attempts in population-based studies: a systematic review of the literature. Addict Behav 2014; 39: 512-519.

21. Smith AL, Carter SM, Chapman S. Why do smokers try to quit without medication or counselling? A qualitative study with ex-smokers. BMJ Open 2015; 5: 007301.

22. Fu SS, Burgess D, Ryn MV. Views on smoking cessation methods in ethnic minority communities: a qualitative investigation. Prev Med 2007; 44: 235-240.

23. Levinson AH, Borrayo EA, Espinoza P. An exploration of Latino smokers and the use of pharmaceutical aids. Am J Prev Med 2006; 31: 167-171. 
24. Kasza KA, Hyland AJ, Borland R. Effectiveness of stopsmoking medications: findings from the International Tobacco Control (ITC) Four Country Survey. Addiction 2013; 108: 193-202.

25. Miller N, Frieden TR, Liu SY. Effectiveness of a largescale distribution programme of free nicotine patches: a prospective evaluation. Lancet 2005; 365: 1849-1854.

26. Alpert HR, Connolly GN, Biener L. A prospective cohort study challenging the effectiveness of population-based medical intervention for smoking cessation. Tob Control 2013; 22: 32-37.

27. Pierce JP, Gilpin EA. Impact of over-the-counter sales on effectiveness of pharmaceutical aids for smoking cessation. JAMA 2002; 288: 1260-1264.

28. Smoking and tobacco use: best practices for comprehensive tobacco control programs-2014. Atlanta,
GA: US Department of Health and Human Services, CDC; 2014. Available at http: //www.cdc.gov/tobacco/ state and community/best_practices

\section{*Correspondence to}

Awad S. Alsamghan

Family and Community Medicine Department

College of Medicine

King Khalid University

Kingdom of Saudi Arabia 